\title{
SIMPLIFIED MOMENT-CURVATURE RELATIONSHIP IN ANALYTICAL FORM FOR CIRCULAR RC SECTIONS
}

\author{
Roberto Gentile ${ }^{1}$, Francesco Porco ${ }^{2}$, Domenico Raffaele ${ }^{3}$ and \\ Giuseppina Uva ${ }^{4}$
}

(Submitted August 2017; Reviewed November 2017; Accepted January 2018)

\begin{abstract}
The behaviour of regular multi-span simply-supported bridges is strongly dependent on the behaviour of its piers. The response of a pier is governed, in general, by different mechanisms: flexure, shear, second order effects, lap-splice of longitudinal bars or their buckling. The flexural behaviour is an important part of the problem, and it can be characterised through the equivalent plastic hinge length and the Moment-Curvature law of the fixed end. In this paper, a procedure to calculate the Moment-Curvature relationship of circular $\mathrm{RC}$ sections is proposed which is based on defining the position of few characteristic points. The analytical formulation is based on adjusted polynomial functions fitted on a database of fibre-based analyses. The proposed solution is based on three parameters: dimensionless axial force, mechanical ratio of longitudinal reinforcement, geometrical ratio of transverse reinforcement. A benchmark case is presented to compare the solution to a FEM non-linear analysis. Even if it is based on few input data, this solution allows to have good indicators on the material performances (e.g. yielding, spalling, etc). For these reasons, the proposed approach is deemed to be particularly effective in performing quick yet accurate mechanics-based regional-scale assessment of bridges.
\end{abstract}

\section{INTRODUCTION}

The seismic vulnerability of existing structures has become a relevant theme in earthquake engineering, and great attention has been devoted to bridge structures, in order to perform vulnerability inventory at a regional scale. In fact, for example, most of the Italian RC bridges were built around the 1960s referring to codes with no "anti-seismic philosophy". Moreover, a bridge can often be a crucial node of a transport web and thus its performance should be guaranteed even in the aftermath of an earthquake. Hence, having an inventory of the structural performances of the bridges in a region is crucial in order to plan mitigation actions. This might be also needed to quickly assess a large group of damaged bridges in the aftermath of an earthquake. The 2016 Kaikoura Earthquake is a clear example of this situation [1]

Considering the large amount of structures involved and the shortage of resources, it is cost-ineffective to perform detailed structural analyses (e.g. non-linear analyses) for the whole portfolio [2]. Therefore, a multi-level approach is usually preferred, by starting from a large-scale analysis at the regional level, in which a first screening and prioritisation is performed by using poor data and simplified models. In the successive stages, the accuracy and detail of the assessment is progressively refined for specific subsets of elements at risk.

Traditionally, regional-scale analysis resorts to typological or semi-empirical vulnerability methods that involve the use of calibrated indexes, e.g. [3]. As a possible approach to manage the regional scale, some researchers have proposed the definition of simplified capacity curves for typological classes fitted on detailed nonlinear analyses for a representative number of "ideal" sample case studies [4]. Alternatively, other classes of simplified methods allow to assess the performance of relatively regular bridges based on a rational mechanical approach, although under simplified assumptions. Provided that the deck remains elastic and the bearings do not fail, the energy dissipation capacity of a bridge is concentrated in the piers [5]. Therefore, the vulnerability of the whole structure can be expressed by studying the capacity curves of the piers, modelled as equivalent SDOF systems, in the transverse and in the longitudinal direction. In this last case, each pier can still be considered as an independent oscillator by considering the "effective" mass pertaining to the adjacent spans. Depending on the direction of the analysis, it is therefore necessary to consider two distinct simplified models characterised by different parameters [6-8]. Based on the fixity condition of the piers, an appropriate shear span length can be defined, and the ForceDisplacement flexural behaviour is defined by the MomentCurvature relationship of a critical section. For simply supported bridges, the critical section is located at the base. For a detailed analysis of a single bridge, Moment-Curvature is typically calculated with a software (e.g. KSU_RC [9], Cumbia [10], etc). The flexural capacity curve can be possibly modified by the occurrence of additional failure mechanisms such as shear, longitudinal bars buckling, lap-slice, second order effects.

In view of a regional-scale analysis for a large portfolio of bridges and of the derivation of probabilistic fragility curves [11-13], it is particularly desirable to have a rapid yet accurate formulation of the Moment-Curvature relationship, which is the specific objective of this paper (Figure 1). In particular, in this study it is proposed a polynomial analytic solution fitted against an extensive dataset of sectional analyses that guarantees an accurate, rapid and computationally inexpensive flexural characterisation of the sections of the piers. Alternatively, for a

1 Corresponding Author, Ph.D. candidate, Department of Civil, Environmental, Land, Building Engineering and Chemistry, Polytechnic University of Bari, Bari, Italy, roberto.gentile@poliba.it

2 Lecturer, Department of Civil, Environmental, Land, Building Engineering and Chemistry, Polytechnic University of Bari, Bari, Italy, francesco.porco@poliba.it

3 Senior Lecturer, Department of Civil, Environmental, Land, Building Engineering and Chemistry, Polytechnic University of Bari, Bari, Italy, domenico.raffaele@poliba.it

4 Associate Professor, Department of Civil, Environmental, Land, Building Engineering and Chemistry, Polytechnic University of Bari, Bari, Italy, giuseppina.uva@poliba.it 


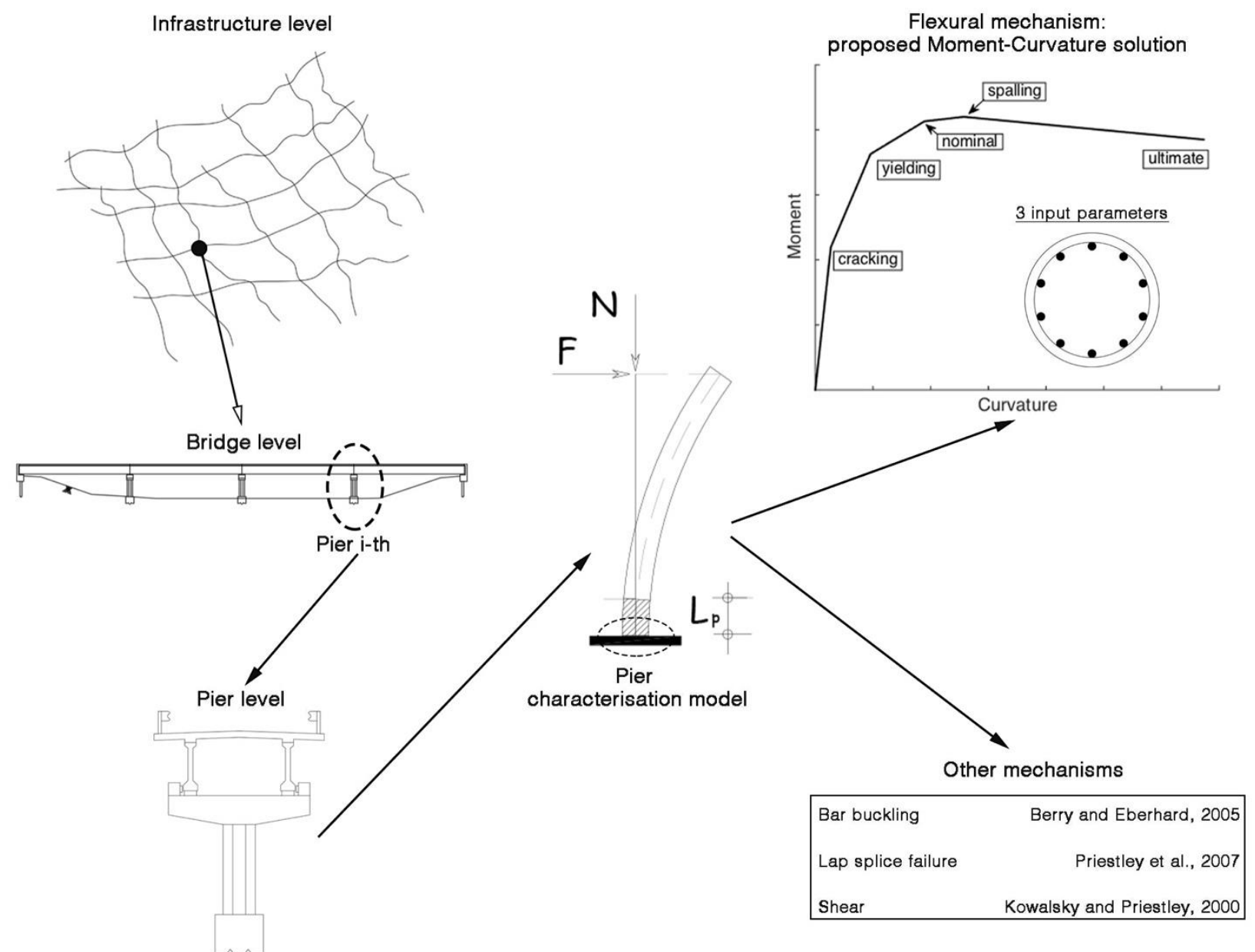

Figure 1: Regional-scale seismic vulnerability of bridges.

detailed assessment, such a rapid formulation can be used to verify and validate the results of the numerical MomentCurvature analyses. Once the simplified Moment-Curvature is calculated, the aforementioned additional mechanisms can be easily introduced in the model by using acknowledged literature studies (shear failure [14], longitudinal bars buckling [15], lapsplice [16], second order effects [17]).

In the paper, the solution for circular sections is presented, but it can be generalised to other section shapes, which are currently being studied.

\section{METHODOLOGY FOR DERIVING THE ANALYTICAL SIMPLIFIED $M-\varphi$ FORMULATION}

The Moment-Curvature $(M-\varphi)$ relationship of RC circular sections is calculated by defining the position of few characteristic points. Each of these is defined in analytical form depending on 3 parameters (also used in other literature studies, e.g. $[18,19])$ : dimensionless axial force, mechanical ratio of longitudinal reinforcement, volumetric ratio of transverse reinforcement. To do so, a database of Moment-Curvature diagrams was created conducting fibre-based analyses (from now on referred to as "exact" numerical solution). The numerical analyses were carried out using the software by Esmaeily and Peterman [9]. The results were processed using MATLAB in order to define the characteristic points of each $(M-\varphi)$ curve. Finally, based on least squares method linear regression, a polynomial relation was calculated for each characteristic moment or curvature (from now on referred to as simplified analytical solution). The approach herein proposed is based on realistic stress-strain relationships for concrete and steel and for this reason the results are particularly accurate. The reliability of the proposed solution is proved analysing a numerical case study pier and comparing the results with a FEM non-linear analysis, showing good agreement.

\section{Definition of the Characteristic Points}

Each software-based $(M-\varphi)$ curve was analysed with a MATLAB function specifically designed for this study. Having as input the Moment-Curvature law in tabular form, the function extracts 7 characteristic points corresponding to different limit states of the section (see Figure 2). Based on these points, a multi-linear approximation of the $(M-\varphi)$ curve can be obtained (an example is given in Figure 3).

The chosen characteristic points are:

Cracking: For the cracking point, a strain of $\varepsilon_{c t}$ is measured in the furthermost concrete fibre in the section (see Figure 2). More specifically, this is the point for which Equation 1 is satisfied. In this equation, $D$ is the diameter of the cross-section, $n$. $a$. is the neutral axis depth, $c$ is the clear cover, $f_{c t}$ is the concrete flexure tensile strength (Equation 6), $\varepsilon_{c}$ is the strain in the furthermost compressed concrete core fibre;

$$
\frac{D-n \cdot a .}{n \cdot a \cdot-c} \varepsilon_{c}=\varepsilon_{c t} \text { where } \varepsilon_{c t}=\frac{f_{c t}}{E_{c}}
$$




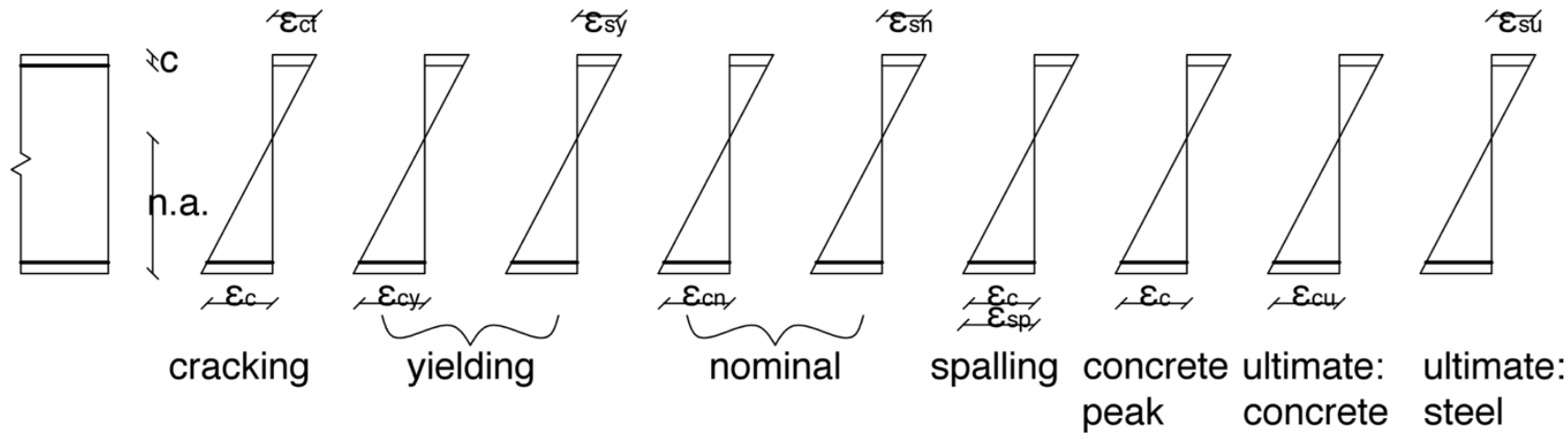

Figure 2: Strain state of the section in the characteristic points.

Concrete Yielding: Defined as the point on the $(M-\varphi)$ curve that corresponds to a strain of $\varepsilon_{c y}=0.002$ in the extreme core concrete fibre in compression.

First Yield: The minimum value between concrete yielding and the point on the $(M-\varphi)$ curve that corresponds to the first tension yielding of the reinforcement bar furthest from the neutral axis [17];

Nominal: This point corresponds to a compressive strain of $\varepsilon_{c}=0.004$ in the extreme core concrete compression fibre or $\varepsilon_{s}=0.015$ in the furthermost tension rebar, whichever occurs first [17];

Spalling: The point on the $(M-\varphi)$ response for which the spalling strain $\varepsilon_{s p}=0.0045$ is induced in the extreme fibre of the cover concrete (Figure 2) according to Equation 2;

$$
\frac{n \cdot a .}{\text { n.a. }-c} \varepsilon_{c}=\varepsilon_{s p}
$$

Peak of Confined Concrete: This point represents the curvature that induces a strain, in the extreme core concrete fibre, equal to its strain at peak stress in the stress-strain relationship (Figure 5). This point can be used to understand the starting of the softening of the concrete;

Ultimate: The last point of the $(M-\varphi)$ curve. The failure of the section can be due to the achievement of the ultimate compressive strain in confined concrete or strain at ultimate stress in the extreme tension rebar.

The transformation in dimensionless form $(m-\chi)$ is done with Equations 3 and 4 , in which $\mathrm{R}$ is the radius of the cross-section and $f_{c}$ is the unconfined concrete strength.

$$
\begin{gathered}
m=\frac{M}{\pi R^{3} f_{c}} \\
\chi=\varphi R
\end{gathered}
$$

\section{CONSTRUCTION OF THE DATABASE}

\section{Basic Parameters}

The parameters involved in the definition of the flexural behaviour of RC circular sections are several: radius $R$, clear cover $c$, axial force $N$, compression strength of concrete in unconfined conditions $f_{c}$, tension strength of concrete $f_{c t}$, concrete modulus of elasticity $E_{c}$, yielding strength of longitudinal and transverse reinforcement $f_{y s}, f_{y h}$, moduli of elasticity of the steel $E_{s}, E_{h}$, number and diameter of longitudinal reinforcement bars $n_{l}, d_{l}$, diameter and spacing of transverse reinforcement $d_{h}, s$

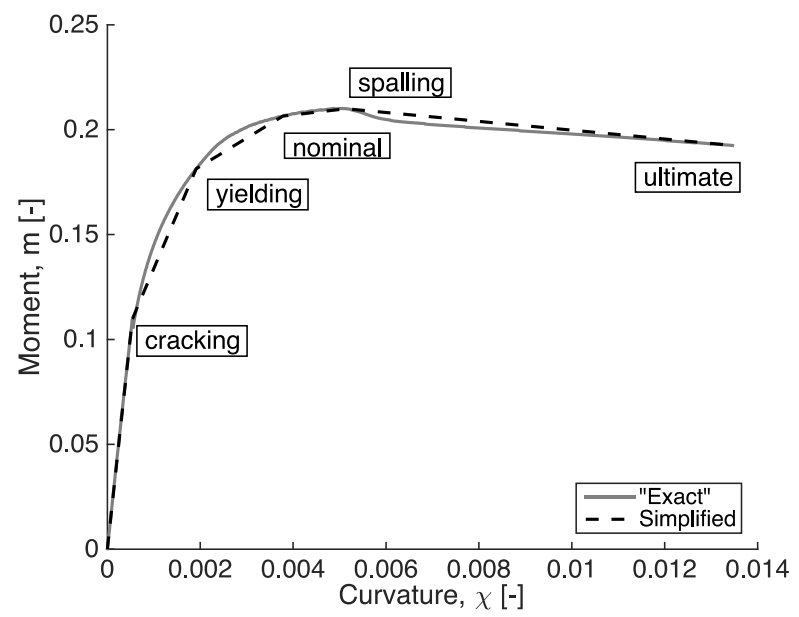

Figure 3: Simplified moment-curvature relationship.

It is clear that, for the purpose of this work, it is inconvenient to have such a large number of parameters and, for this reason, some assumptions were adopted:

- concrete tensile strength $f_{t}$ (for uniform tensile stress) was related to its compression strength $\left(f_{c}\right)$ according to Equation 5, provided in the Italian code [21]. Moreover, Equation 6 was used in order to consider the tensile strength appropriate for flexure actions $\left(f_{c t}\right)$. This choice is not likely to limit the field of application of the final formulations, since it only affects the cracking point of the Moment-Curvature law;

$$
\begin{aligned}
& f_{t}=0.3 f_{c}^{2 / 3} \\
& f_{c t}=1.2 f_{t}
\end{aligned}
$$

- longitudinal and transverse reinforcement steel have the same yield stress $\left(f_{y s}, f_{y h}\right.$ respectively) and elastic modulus $\left(E_{S}, E_{h}\right.$ respectively), according to Equation 7;

$$
f_{y h}=f_{y s} \text { and } E_{h}=E_{s}
$$

- longitudinal reinforcement is composed by $n_{l}$ evenly distributed bars of equal diameter $d_{l}$. The total area of longitudinal steel is defined with Equation 8;

$$
A_{s}=\frac{n_{l}\left(\pi d_{l}^{2}\right)}{4}
$$


- the clear cover, $c$, is proportional to the radius of the section according to Equation 9;

$$
c=0.05 R
$$

- the diameter is fixed to $1 \mathrm{~m}$. This was done considering that the relationship between a given limit state curvature and the diameter of the section is linear (see, for example [17], in which this is shown for yielding and ultimate curvature).

The remaining parameters of the problem were grouped into 3 dimensionless parameters based on dimensional analysis (axial force ratio $v$, mechanical ratio of longitudinal reinforcement $\omega$, volumetric ratio of transverse reinforcement $\rho_{s p}$ ) so that a given circular RC section can be completely defined by them.

The idea is that a variation in $v$ (Equation 10) can be interpreted as a variation in the normal force $N$, the concrete compression strength $f_{c}$ or the radius $R$. An analogous idea applies for Equations 11 and 12 .

$$
\begin{gathered}
v=\frac{N}{\pi f_{c} R^{2}} \\
\omega=\frac{A_{s} f_{y}}{\pi f_{c} R^{2}} \\
\rho_{s p}=\frac{4 A_{s p}}{(2 R-2 c) s}
\end{gathered}
$$

\section{Range of Parameters}

The discrete values of the basic parameters used to construct the database are listed in Table 1. It is clear that some of the studied values are greater than the maximum expected ones for real existing bridge piers. Those were added to the database for the sake of completeness, and to study the trends of the characteristic points of the $(M-\varphi)$ curve.

Table 1: Range of parameters.

\begin{tabular}{cr} 
Parameter & Values \\
\hline$v$ & $0,0.1,0.2,0.3,0.4,0.5,0.6,0.7,0.8,0.9,1$ \\
$\omega$ & $0.05,0.1,0.2,0.4,0.6,0.8$ \\
$\rho_{s p}$ & $0,0.001,0.002,0.004,0.006,0.008,0.01$ \\
\hline
\end{tabular}

For the analyses in the database, the values $R=1 \mathrm{~m}$ and $f_{c}=$ $31.83 \mathrm{MPa}$ were fixed and the value of $N$ corresponding to $v$ was calculated according to Equation 10. Analogously, $f_{y}=$ $450 \mathrm{MPa}$ and $n_{l}=22$ were fixed so the cross-sectional area of a single rebar was calculated using Equations 11 and 8. It is worth mentioning that since the relationship between steel yield stress and strength of the cross-section can be assumed to be linear [17], this choice is unlikely to limit the scope of the simplified formulations proposed in this paper.

Fixing the clear cover (Equation 9), the spacing of the stirrups $(s=0.1 \mathrm{~m})$, and the other above-mentioned values, the crosssectional area of the stirrup was calculated using Equation 12.

\section{Execution of the Analyses}

Based on the chosen discrete values of the input parameters, a Moment-Curvature analysis was conducted for each combination of them $(11 \times 6 \times 7=462$ combinations $)$. The analyses were carried out with the software KSU-RC [9]. The fibre discretisation of the cross-section adopted in the analyses is shown in Figure 4.

The relationship proposed in Mander et al. [20] was used for concrete, considering the confined and unconfined behaviour (Figure 5). It is worth mentioning that confined concrete ultimate strain was limited to 0.02 when the calculation according to Mander et al. [20] yielded higher values.

The behaviour of steel was modelled with the stress-strain relationship shown in Figure 6, proposed in Reference [9]. The curve is linear up to yielding, with a plateau up to a strain of $K_{1}$ times the yielding strain and followed by a parabolic shape. The peak corresponds to a strain of $K_{2}$ times the yielding strain and a strain of $K_{3}$ times the yielding strain corresponds to the ultimate strain point at rupture. $K_{4}$ is the tensile strength to yield stress ratio. These parameters were fine-tuned to be representative of a commercial steel with a nominal yield stress ranging between 400 and $500 \mathrm{MPa}$ (e.g. the Italian B450C [21] and the New Zealand grade 500 [22, 23]). $K_{1}=10$ was used to model the length of the yield plateau. Recent research [24] corroborates this choice. The remaining parameters are: $K_{2}=$ $30, K_{3}=55, K_{4}=1.3$. It is worth mentioning that 0.06 was adopted as steel ultimate strain, to implicitly consider low cycle fatigue failure, as suggested in the 2017 New Zealand guidelines for seismic assessment [22]. Figure 6 shows that, with these assumptions, the adopted stress-strain relationship is in close agreement with the widely utilised curve proposed in King et al. [25]. This is deemed to indirectly demonstrate the suitability of the adopted stress-strain curve.
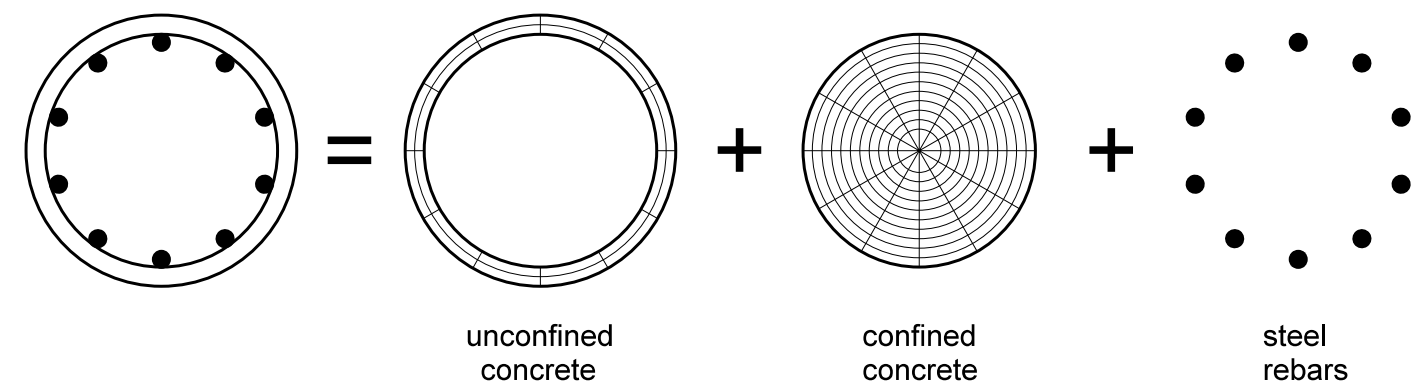

Figure 4: Cross-section fibre model. 


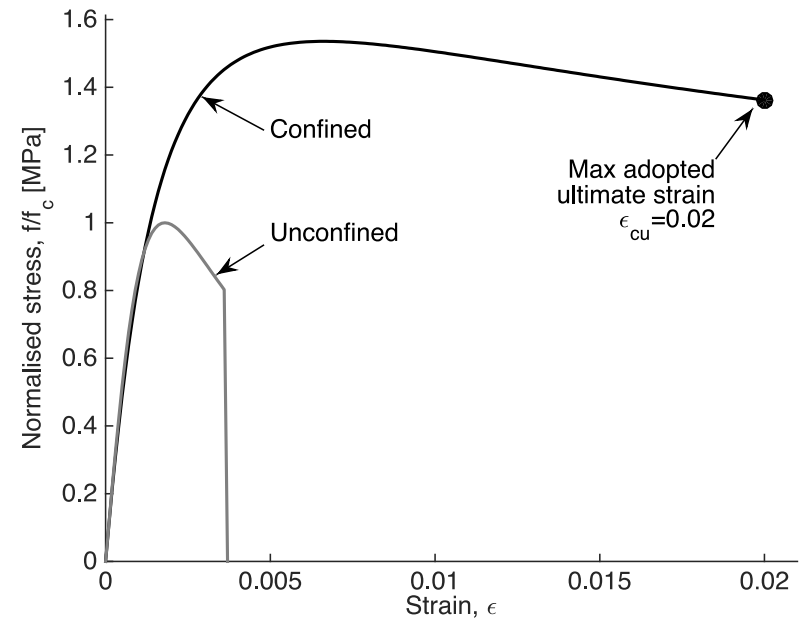

Figure 5: Concrete stress-strain relationship.

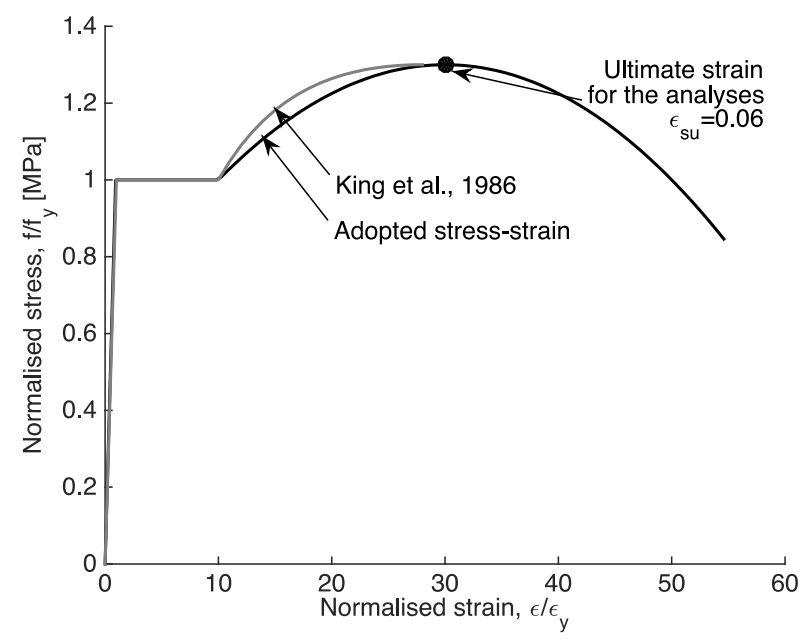

Figure 6: Steel stress-strain relationship

\section{POST PROCESSING}

A study was conducted to investigate the variability of the characteristic moments and curvatures with respect to the fundamental parameters chosen. In Figure 7, the trend of the most meaningful characteristic points is represented as a function of the dimensionless axial force, $v$, and a fixed value of both longitudinal $(\omega)$ and transverse reinforcement $\left(\rho_{s p}\right)$ ratios. In Appendix A some more synthetic plots are represented that account for the variability of the parameters $\omega$ and $\rho_{s p}$. In such plots (Figure 13 to Figure 18), the mechanical ratio of the longitudinal reinforcement, $\omega$, is fixed, each characteristic point has a different line colour (e.g. green is for yielding), and the line width increases with the increase of the volumetric ratio of transverse reinforcement (the dashed line is for unconfined).

\section{CURVE FITTING}

By knowing the values of the characteristic moments and curvatures for each case in the database, 14 polynomials in three variables (axial load ratio, mechanical ratio of longitudinal reinforcement, volumetric ratio of transverse reinforcement) were calibrated to fit the data based on a least square method linear regression. It is noteworthy that the cases in which $\rho_{s p}=$ 0 were studied only for control purposes and so they were excluded from the fitting. For the same reason, the cases with $v=0.9$ and $v=1$ were excluded too. It is worth mentioning that the results of the parametric analysis, Figure 13 to Figure 18 , can be adopted to manually construct "by-hand" the capacity curve of a given RC circular section. Nonetheless, it is deemed that the adjusted polynomial functions are more effective if a great number of applications is needed, since they can be easily implemented in a spreadsheet or a computer routine.
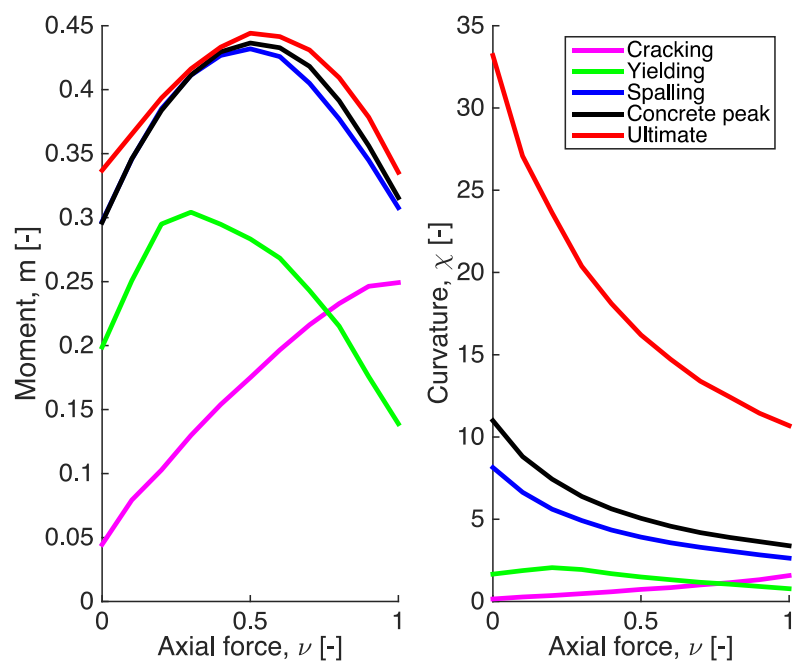

Figure 7: Trend of the characteristic moments and curvatures for $\omega=0.4$ and $\rho_{s p}=0.006$.

The degree of the polynomials in each of the three variables was chosen based on the trends represented in Figure 13 to Figure 18. The coefficients of the fitting were defined in such a way that a p-value smaller than 5\% was obtained for all of them. Although this is not a statistical study, it is worth mentioning that the adjusted R-squared parameter is 0.99 for the moment polynomials and ranges between 0.90 and 0.99 for the curvature ones. The structure of the polynomials is described in Equations 13 and 14, while the $a_{i}$ coefficients for each function are given in Table 5 and Table 6, in Appendix A.

$$
\begin{aligned}
\chi_{\text {char }}=a_{0}+a_{1} v & +a_{2} \omega+a_{3} \rho_{s p}+a_{4} v^{2}+a_{5} v \omega \\
& +a_{6} \omega^{2}+a_{7} v \rho_{s p}+a_{8} \omega \rho_{s p} \\
& +a_{9} v^{3}+a_{10} v^{2} \omega+a_{11} v \omega^{2} \\
& +a_{12} v^{2} \rho_{s p}+a_{13} v \omega \rho_{s p} \\
& +a_{14} \omega^{2} \rho_{s p} . \\
m_{\text {char }}=a_{0}+a_{1} v & +a_{2} \omega+a_{3} \rho_{s p}+a_{4} v^{2}+a_{5} v \omega \\
& +a_{6} \omega^{2}+a_{7} v \rho_{s p}+a_{8} \omega \rho_{s p} \\
& +a_{9} v^{3}+a_{10} v^{2} \omega+a_{11} v \omega^{2} \\
& +a_{12} v^{2} \rho_{s p}+a_{13} v \omega \rho_{s p} \\
& +a_{14} \omega^{2} \rho_{s p}+a_{15} \rho_{s p}^{2} .
\end{aligned}
$$

\section{ULTIMATE CURVATURE CORRECTION FACTOR}

Concrete compressive strength was not explicitly considered as an input value for the database, since the analyses were conducted assuming $f_{c}=31.83 \mathrm{MPa}$. According to the energybased assumptions in Mander's model, the ultimate strain of confined concrete depends on the compressive strength of unconfined concrete. In particular, fixing the ratio of transverse reinforcement, the greater the compressive strength the less the ultimate strain of confined concrete. For a given value of $\rho_{s p}$, the relationship between ultimate strain of confined concrete and strength of unconfined concrete is parabolic (as shown in Figure 8). A similar pattern is to be expected for the ultimate curvature, strongly correlated to concrete ultimate strain.

To capture this trend, a sensitivity analysis with respect to $f_{c}$ was carried out and a correction factor for the ultimate curvature polynomial was calculated. A group of RC sections was defined 
with different values of $f_{c}$ but equal value of the parameters $v$, $\omega$ and $\rho_{s p}$ (Equations 10, 11 and 12). For each of them, a Moment-Curvature analysis and a post-processing were conducted, calculating the ultimate dimensionless curvature $\chi_{u}\left(f_{c}\right)$. The same values, named $\chi_{u}(31.83)$, were predicted with the ultimate curvature polynomial. The ratios of the abovementioned parameters were used to fit the 2nd-order polynomial "Correction Factor (CF)", shown in Equation 15 This allows to take into account the appropriate value of the concrete strength and correct the ultimate curvature prediction according to Equation 16. Basically, the ultimate curvature is calculated multiplying the value predicted according to the ultimate curvature polynomial (depending on $v, \omega, \rho_{s p}$ ) to correction factor (which depends on $f_{c}$ ).

$$
\begin{gathered}
C F=\frac{\chi_{u}\left(f_{c}\right)}{\chi_{u}(31.83)}= \\
=0.000738 f_{c}^{2}-0.078268 f_{c}+2.747041 \\
\chi_{u}\left(f_{c}\right)=C F \chi_{u}(31.83)
\end{gathered}
$$

Figure 9 shows, respectively for $f_{c}=20 \mathrm{MPa}$ and $f_{c}=$ $50 M P a$, the comparison of the "exact" $(M-\varphi)$ diagram (dashdot line), the simplified one with (solid line) or without (dashed line) using the correction factor. It is clear that using the "noncorrected" polynomial, the ultimate curvature is underpredicted for $f_{c}=20 \mathrm{MPa}$ and over-predicted for $f_{c}=50 \mathrm{MPa}$. The "corrected" version leads to a very good match with the "exact" solution in terms of ultimate curvature.

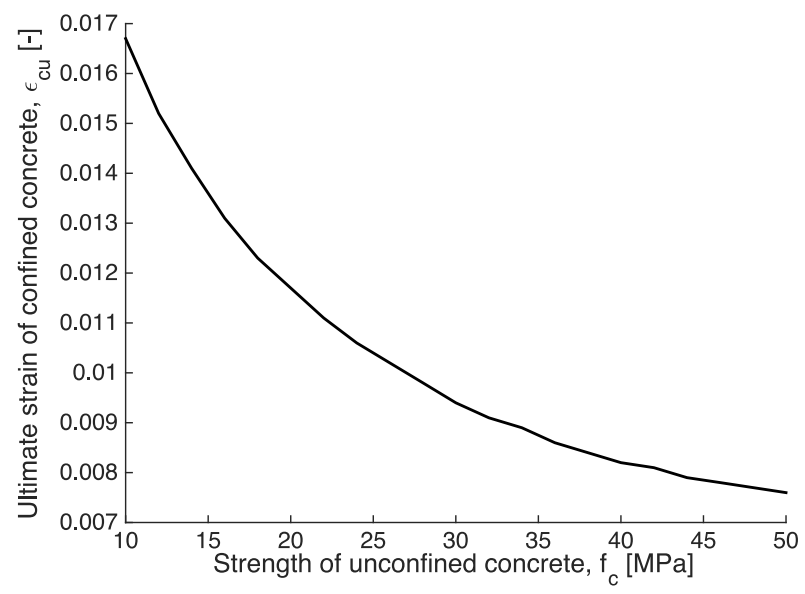

\section{Figure 8: Ultimate strain of confined concrete with respect to the unconfined concrete strength for an equal value of volumetric ratio of transverse reinforcement.}

\section{ACCURACY OF THE FUNCTIONS}

The polynomials that allow the construction of the $(M-\varphi)$ curve were tested with the procedure that follows. A group of $10 \mathrm{RC}$ circular sections was defined with random yet plausible values of the input parameters (shown in Table 7, in Appendix A). Each "test case" was analysed (with the same procedure used for the database) to obtain the characteristic moments and curvatures. Then the polynomials herein proposed were used to predict the same values (the ultimate curvature was multiplied by the correction factor).
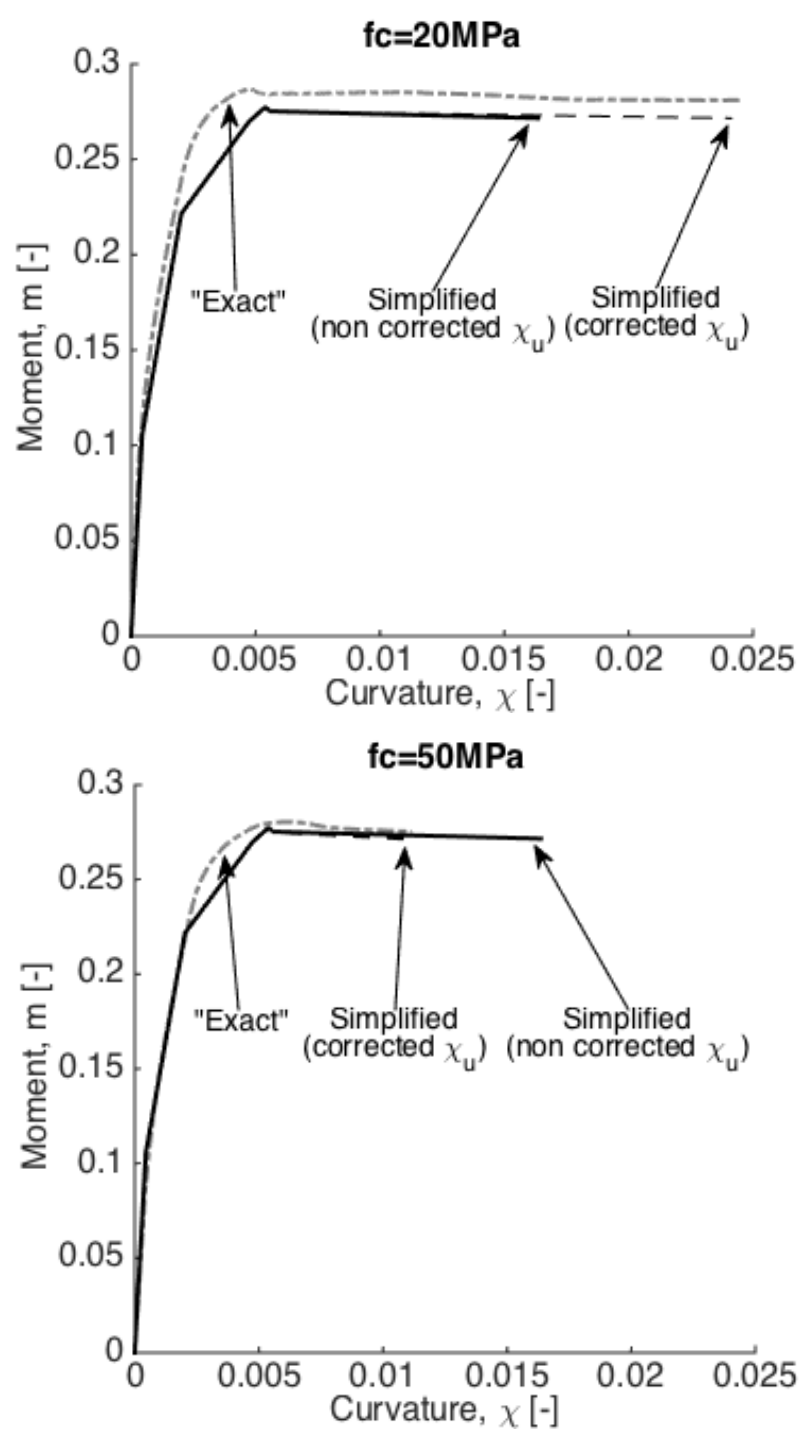

Figure 9: Role of the ultimate curvature correction factor.

According to Equation 17, the error $(E R R)$ of each prediction was calculated and a global error $\left(E R R_{\text {glob }}\right)$ was defined by Equation 18 (shown in Table 2). For the characteristic moments, an under prediction lower than $11 \%$ is registered, except for the ultimate moment $(15.9 \%)$. On the other hand, more scatter is registered for the characteristic curvatures, with a considerably smaller absolute error. These trends are shown in detail in Figure 10 through predicted vs measured plots, comprehensive of the full dataset used for the curve fitting. This gives a complete overview of the accuracy of the proposed model.

$$
\begin{gathered}
\text { Err }=100\left|\frac{\text { measured-predicted }}{\text { measured }}\right|[\%] \\
\operatorname{Err}_{\text {glob }}=\frac{\sum_{i=1}^{10} \text { Err }_{i}}{10}[\%]
\end{gathered}
$$

\section{NUMERICAL APPLICATION}

The aim of this section is to demonstrate that the proposed simplified procedure to evaluate the Moment-Curvature diagram of an RC cross-section is a reliable input for the assessment of the performance of a bridge pier. Therefore, a numerical validation of the above-mentioned procedure is presented herein. It is assumed that the geometric and mechanical parameters of an ideal bridge pier, belonging to a simply-supported bridge, are the ones listed in Table 3. 
Table 2: Global error [\%] of the functions, related to 10 test sections.

\begin{tabular}{ccccccccccccccc} 
& $\chi \chi_{\mathbf{C R}}$ & $\chi \mathbf{Y c}$ & $\chi \mathbf{Y}$ & $\chi \mathbf{P}$ & $\chi_{\mathbf{N}}$ & $\chi \mathbf{S P}$ & $\chi_{\mathbf{U}}$ & $\mathbf{m}_{\mathbf{C R}}$ & $\mathbf{m}_{\mathbf{Y c}}$ & $\mathbf{m}_{\mathbf{Y}}$ & $\mathbf{m}_{\mathbf{P}}$ & $\mathbf{m}_{\mathbf{N}}$ & $\mathbf{m}_{\mathbf{S P}}$ & $\mathbf{m}_{\mathbf{U}}$ \\
\hline $\mathrm{ERR}_{\mathrm{glob}}$ & 10.1 & 10.4 & 6.6 & 11.9 & 5.7 & 5.6 & 4.9 & 6.0 & 10.7 & 11.1 & 7.1 & 4.2 & 3.9 & 15.9 \\
\hline
\end{tabular}
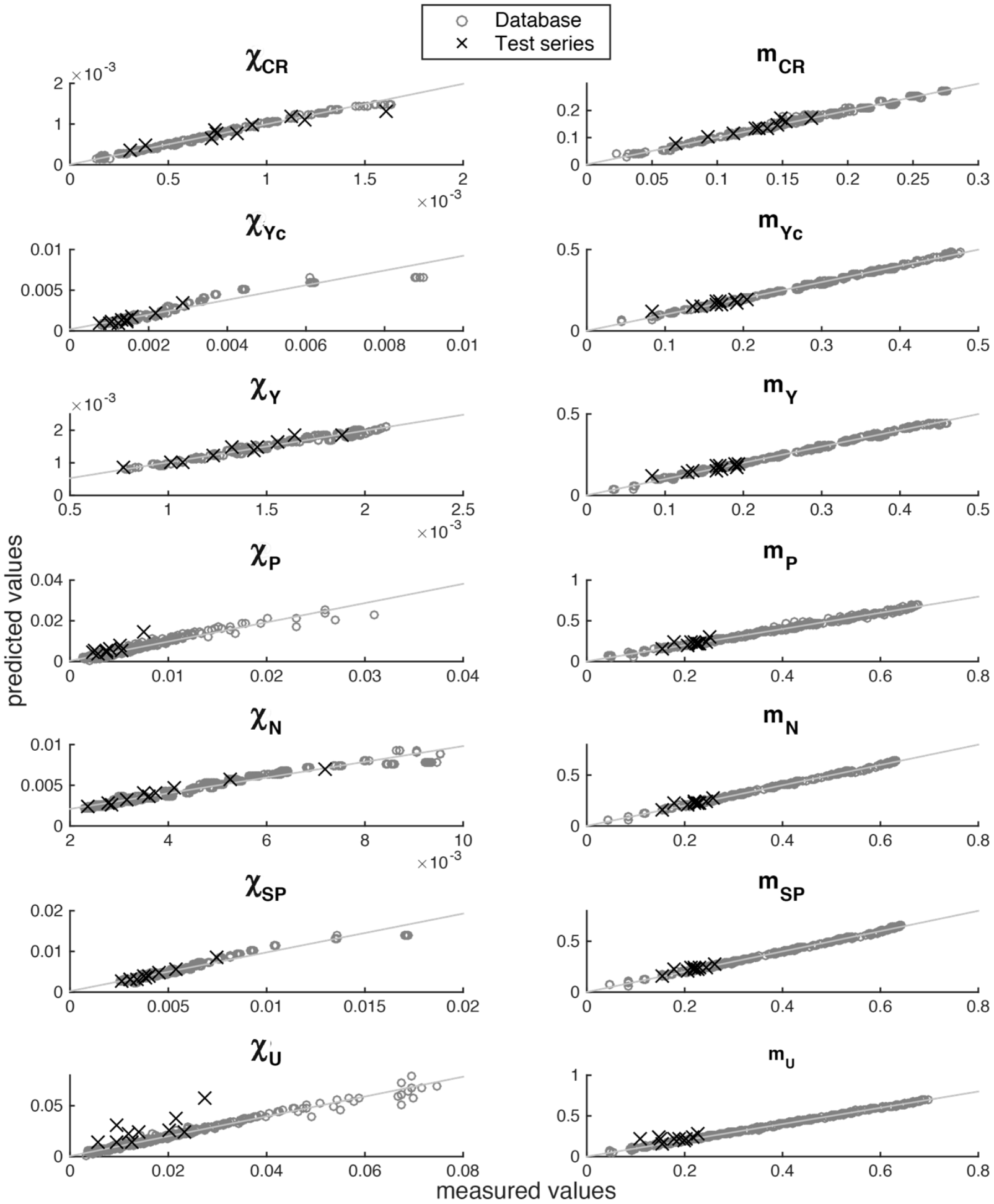

Figure 10: Predicted vs measured plots. 
It is worth noting that the behaviour of the pier depends on the presence of seismic restraints and this can be taken into account in a simplified way by considering the effective mass pertaining to the pier itself [6]. For this reason, it is necessary to conduct two separate analyses, one for the transverse and one for the longitudinal direction, varying the axial force on the pier.

The flexural behaviour of the base section of the pier was predicted using the characteristic polynomials (Equations 13 and 14) and transformed in dimensional form according to Equations 3 and 4 . The Force-Displacement $(F-\delta)$ relationship was calculated according to Equations 19 and 20, in which $\varphi$ is the curvature, $\varphi_{Y}$ is the yield curvature, $M$ is the moment, $L$ is the length of the pier and $L_{p}(=0.64 m)$ is the plastic hinge length, calculated according to Priestley and Park [26].

This curve might be "corrected" in order to take into account the different mechanisms, but the benchmark case was chosen in such a way that the collapse was only governed by axial force and bending: therefore, no additional action was needed. In Figure 11, the simplified $(M-\varphi)$ diagrams are compared to the "exact" numerical sectional analysis, carried out with KSU_RC [9], SAP2000 [27] and Cumbia [10]. A very good match is registered, with a modest overestimation of the moment in the post-yielding branch (numerical values are discussed below).

$$
\begin{gathered}
\delta= \begin{cases}\frac{\varphi L^{2}}{3} & \text { if } \varphi \leq \varphi_{Y} \\
\frac{\varphi_{Y} L^{2}}{3}+\left(\varphi-\varphi_{Y}\right) L_{p}\left(L-0.5 L_{p}\right) & \text { if } \varphi>\varphi_{Y}\end{cases} \\
F=\frac{M}{L}
\end{gathered}
$$

The pier was also modelled by means of 12 "beam" elements using the FEM software SAP2000 V18 [27]. Using the "Fiber P M2 M3 hinge", the cross-section was discretised into 600 fibres assigning the same constitutive laws used in the database. The pier was studied through a displacement-control Pushover analysis under a horizontal force applied to the tip of it. The obtained capacity curve is compared to the one calculated according to Equation 19 (Figure 12). The results obtained with the simplified procedure are particularly close to the "exact" FEM solution, reflecting the trends registered for the MomentCurvature. This is confirmed in Table 4, which shows the analytical-to-numerical errors, calculated for force and displacement at the peak of the curve $\left(\delta_{\text {peak }}, F_{\text {peak }}\right)$ and at the ultimate condition $\left(\delta_{\mathrm{u}}, \mathrm{F}_{\mathrm{u}}\right)$.

\begin{tabular}{|c|c|c|c|c|c|c|c|c|c|c|c|c|c|}
\hline & $\begin{array}{r}\mathrm{L} \\
(\mathrm{m})\end{array}$ & $\begin{array}{r}D \\
(m)\end{array}$ & $\begin{array}{r}c \\
(m)\end{array}$ & $\begin{array}{l}\mathbf{n}_{\mathbf{l}} \\
(-)\end{array}$ & $\begin{array}{r}d_{1} \\
(m m)\end{array}$ & $\begin{array}{l}d_{h} \\
(-)\end{array}$ & $\begin{array}{r}\mathrm{s} \\
(\mathrm{mm})\end{array}$ & $\begin{array}{r}f_{c} \\
(\mathrm{MPa})\end{array}$ & $\begin{array}{r}f_{y s} \\
(\mathrm{MPa})\end{array}$ & $\begin{array}{r}\mathrm{N} \\
(\mathrm{MN})\end{array}$ & $\begin{array}{r}v \\
(-)\end{array}$ & $\begin{array}{l}\omega \\
(-)\end{array}$ & $\begin{array}{r}\rho_{\text {sp }} \\
(-)\end{array}$ \\
\hline Transverse & 6 & 2 & 0.05 & 30 & 26 & 16 & 70 & 20 & 450 & 13.87 & 0.221 & 0.114 & 0.006 \\
\hline Longitudinal & 6 & 2 & 0.05 & 30 & 26 & 16 & 70 & 20 & 450 & 17.85 & 0.284 & 0.114 & 0.006 \\
\hline
\end{tabular}

Table 3: Geometric and mechanical properties of the example pier.
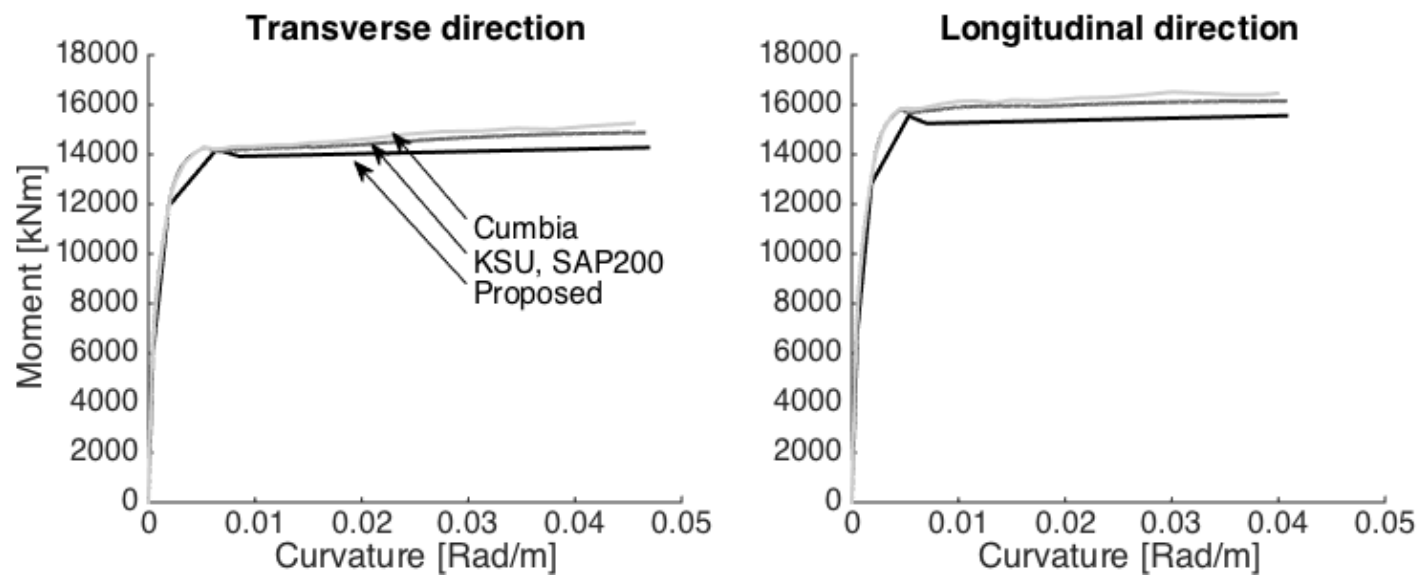

Figure 11: Moment-Curvature: comparison between "exact" and simplified procedure, transverse and longitudinal direction.
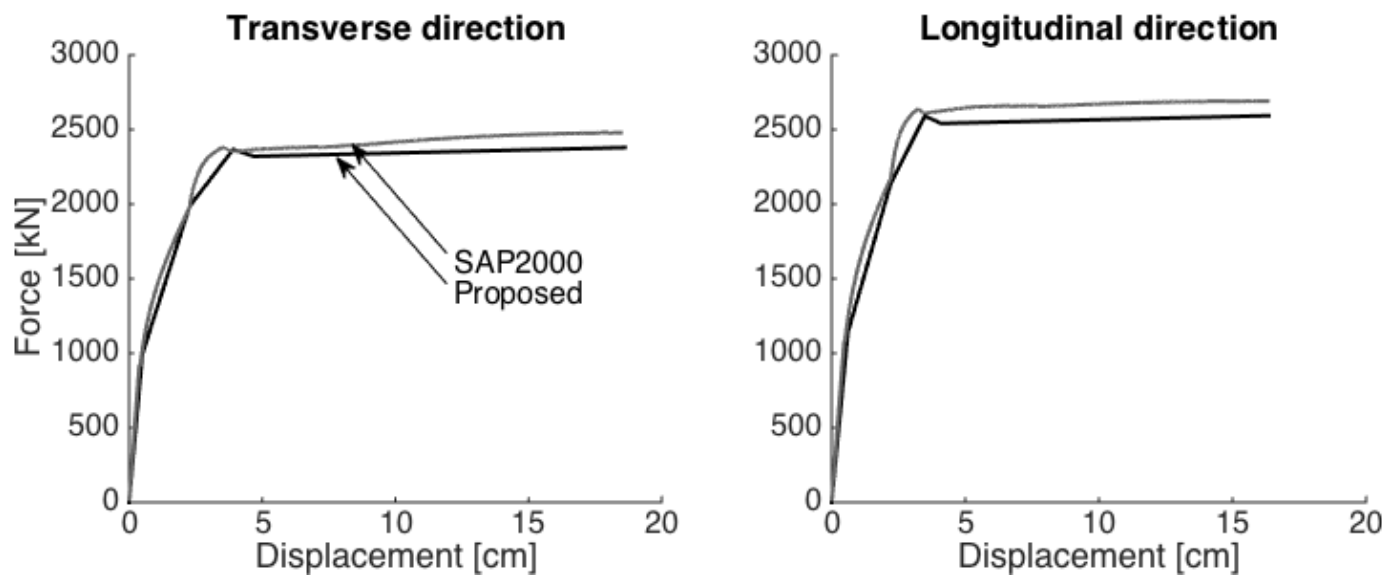

Figure 12: Comparison of the pier capacity curves, transverse and longitudinal directions. 
Table 4: Simplified vs refined FEM analyses: numerical comparison of the results.

\begin{tabular}{lrrrr} 
& $\mathbf{d}_{\text {peak }}$ & $\mathbf{F}_{\text {peak }}$ & $\mathbf{d}_{\mathbf{u}}$ & $\mathbf{F}_{\mathbf{u}}$ \\
\hline Transverse & $11.43 \%$ & $-0.55 \%$ & $0.43 \%$ & $-4.03 \%$ \\
Longitudinal & $10.48 \%$ & $-1.41 \%$ & $-0.18 \%$ & $-3.64 \%$ \\
\hline
\end{tabular}

\section{CONCLUSIONS AND FURTHER DEVELOPMENTS}

This paper deals with the development of a polynomial solution for the characterisation of the flexural behaviour of RC circular bridge piers. In particular, it is proposed to calculate the Moment-Curvature relationship of RC circular sections by defining the position of few characteristic points. Each of these is defined in analytical form depending on 3 parameters: dimensionless axial force, mechanical ratio of longitudinal reinforcement, volumetric ratio of transverse reinforcement. The solution is based on polynomial functions fitted against a large database of fibre-based numerical Moment-Curvature diagrams. The proposed procedure was compared to a refined non-linear FEM model showing good match.

The polynomial formulation is particularly effective within the framework of the regional seismic assessment of RC bridges, in order to perform a large number of analyses and derive probabilistic fragility curves. The use of such a mechanicallybased method, instead of commonly-used empirical methods based on calibrated indices, guarantees much more accuracy and management of uncertainty. On the other hand, the intrinsic simplicity of the proposed solution allows to perform the required large number of analyses with a negligible computational effort. The formulation is well suited for the implementation within computer-based automatic procedures. Other significant section shapes are currently being analysed, in order to provide a more flexible and general assessment tool.

\section{ACKNOWLEDGMENTS}

The research presented in this paper was partially funded by the Project ReLUIS-DPC 2014-2018, "Linea C.A." - R.U. Politecnico di Bari (G.Uva) and the FRA 2012 project (Politecnico di Bari, D.Raffaele).

\section{REFERENCES}

1 Palermo A, Liu R, Rais A, McHaffie B, Andisheh K, Pampanin S, Gentile R, Nuzzo I, Graniero M, Loporcaro G, McGann C and Wotherspoon L (2017). "Performance of road bridges during the $14^{\text {th }}$ November 2016 Kaikoura earthquake". Bulletin of the New Zealand Society for Earthquake Engineering, 50(2): 253-270.

2 Pinho R, Monteiro R, Casarotti C and Delgado R (2009). "Assessment of Continuous Span Bridges through Nonlinear Static Procedures". Earthquake Spectra, 25(1): 143-159.

3 Kircher CA, Whitman RV and Holmes WT (2006). "HAZUS Earthquake Loss Estimation Methods". Natural Hazard Review, 7:45-59.

4 Broglio S, Crowley H and Pinho R (2010). "Simplified Capacity Curves for RC Bridges". Proceedings of $14^{\text {th }}$ European Conference on Earthquake Engineering, Ohrid, Republic of Macedonia, 30/08/2010-03/09/2010.

5 Fardis MN (2007). "Risk Mitigation for Earthquakes and Landslides. Guidelines for Displacement-Based Design of Buildings and Bridges". Report No. 5/2007, IUSS Press, Pavia, Italy.

6 Raffaele D, Porco F, Fiore A and Uva G (2014). "Simplified vulnerability assessment of reinforced concrete circular piers in multi-span simply supported bridges". Structure and Infrastructure Engineering, 10(8): 950-962.

7 Raffaele D, Porco F, Uva G and Fiore A (2014). "Simplified assessment of seismic retrofitting interventions on $\mathrm{RC}$ circular piers in multi-span simply sup- ported bridges". Proceedings of the 7th International Conference on Bridge Maintenance, Safety and Management, Shanghai, China, 07-11/07/14. 2245-2252.

8 Raffaele D, Uva G, Porco F and Fiore A (2014). "About of seismic capacity of bridge piers: A simplified approach". Proceedings of the 7th International Conference on Bridge Maintenance, Safety and Management, Shanghai, China, 07-11/07/14. 2245-2252.

9 Esmaeily A and Peterman RJ (2007). "Performance analysis tool for reinforced concrete members". Computers and Concrete, 4(5): 331-346.

10 Montejo LA and Kowalsky MJ (2007). "Set of Codes for the Analysis of Reinforced Concrete Members". Technical Report No. IS-07-01, North Carolina State University, USA.

11 Padgett JE, Nielson BG and Desroches R (2008). "Selection of optimal intensity measures in probabilistic seismic demand models of highway bridge portfolios". Earthquake Engineering and Structural Dynamics, 37: 711-725.

12 Zelaschi C, Monteiro R and Pinho R (2015). "Improved fragility functions for RC bridge populations". Proceedings of the 5th ECCOMAS Thematic Conference on Computational Methods in Structural Dynamics and Earthquake Engineering, Crete Island, Greece, 25-27 May 2015.

13 Miano A, Fatemeh J, De Risi R, Prota A and Manfredi G (2015). "A Case-Study on scenario-based probabilistic seismic loss assessment for a portfolio of bridges". Proceedings of the 12th International Conference on Applications of Statistics and Probability in Civil Engineering, ICASP12, Vancouver, Canada, 12$15 / 07 / 2015$

14 Kowalsky MJ and Priestley MJN (2000). "Improved Analytical Model for Shear Strength of Circular Reinforced Concrete Columns in Seismic Regions". ACI Structural Journal, 97-S42: 388-396.

15 Berry MP and Eberhard MO (2005). "Practical Performance Model for Bar Buckling". Journal of Structural Engineering, 131(7): 1060-1070.

16 Priestley MJN, Seible F and Calvi G (1996). "Seismic Design and Retrofit of Bridges". John Wiley and Sons, New York, USA, 686 pp.

17 Priestley MJN, Calvi GM and Kowalsky MJ (2007). "Displacement Based Seismic Design of Structures". IUSS Press, Pavia, Italy, $721 \mathrm{pp}$.

18 Peruš I, Poljan`sek K and Fajfar P (2006). "Flexural deformation capacity of rectangular RC columns determined by the CAE method". Earthquake Engineering and Structural Dynamics, 35(12): 1453-1470.

19 Peruš I and Fajfar P (2007). "Prediction of the force-drift envelope for RC columns in flexure by the CAE method". Earthquake Engineering and Structural Dynamics, 36(15): 2345-2363.

20 Mander JB, Priestley MJN and Park R (1988). "Theoretical Stress Strain Model for Confined Concrete”. Journal of Structural Engineering, 114(8): 1804-1826.

21 NTC2008, Ministero delle Infrastrutture e dei Trasporti (2008). "DM 14 gennaio 2008 in materia di "norme tecniche per le costruzioni”. Gazzetta ufficiale n.29 del 4 
febbraio 2008, Supplemento ordinario n.30”. Istituto Poligrafico e Zecca dello stato (in Italian).

22 NZSEE/MBIE (2017). "The Seismic Assessment of Existing Buildings Technical Guidelines for Engineering Assessments". Final draft, 1 July 2017, New Zealand.

23 Loporcaro G (2017). "A Least Invasive Method to Estimate the Residual Strain Capacity in Earthquake-damaged Buildings". PhD Dissertation, University of Canterbury, Christchurch, New Zealand, 250 pp.

24 Sadowski AJ, Rotter JM, Stafford PJ, Reinke T and Ummenhofer $\mathrm{T}$ (2017). "On the gradient of the yield plateau in structural carbon steels". Journal of Constructional Steel Research, 130: 120-130.

25 King DJ, Priestley MJN and Park R (1986). "Computer Programs for Concrete Column Design”. Research Report 86/12, Department of Civil Engineering, University of Canterbury, Christchurch, New Zealand.

26 Priestley MJN and Park R (1987). "Strength and ductility of concrete bridge columns under seismic loading". ACI Structural Journal, 84(1): 61-76.

27 Computer and Structures (2016). "SAP2000 v18. Structural Analysis Program, Manual”. Berkeley, California, USA. 


\section{LIST OF SYMBOLS}

- $a_{i} \quad \mathrm{i}^{\text {th }}$ coefficient of the characteristic polynomials

- $A_{s p} \quad$ cross-sectional area of one stirrup

- c clear cover of the cross-section

- $\quad C F \quad$ ultimate curvature correction factor

- D diameter of the cross-section

- $\delta \quad$ displacement at the tip of the pier

- $d_{h} \quad$ diameter of one stirrup

- $d_{l} \quad$ diameter of one longitudinal bar

- $\varepsilon_{c} \quad$ concrete strain

- $\varepsilon_{c t} \quad$ concrete strain @ tensile strength

- $\varepsilon_{s p} \quad$ concrete spalling strain

- $E_{c} \quad$ concrete elastic modulus

- $E_{h}$ transverse steel elastic modulus

- $E_{s} \quad$ longitudinal steel elastic modulus

- $\quad E r r$ error for a single entry of the test series

- $E r r_{g l o b}$ global error of one polynomial (related to the test series)

- $F$ force

- $f_{c}$ unconfined concrete cylinder compressive strength

- $f_{c t} \quad$ concrete tensile strength (flexure)

- $f_{t} \quad$ concrete tensile strength (pure tension)
- $f_{y h} \quad$ transverse steel yield stress

- $f_{y s} \quad$ longitudinal steel yield stress

- $\varphi \quad$ curvature

- $\varphi_{Y} \quad$ yield curvature

- $\chi$ dimensionless curvature

- $\chi_{\text {char }}$ curvature for one characteristic point

- $\chi_{u}\left(f_{c}\right)$ dimensionless ultimate curvature for a given value of $f_{c}$

- $\quad \chi_{u}(31.83)$ dimensionless ultimate curvature for $f_{c}=$ $31.83 \mathrm{MPa}$

- $\quad L \quad$ length of the pier

- $L_{p} \quad$ equivalent plastic hinge length

- M moment

- m dimensionless moment

- mar moment for one characteristic point

- $n_{l}$ number of longitudinal bars in the crosssection

- N axial load

- n.a. neutral axis depth

- $\mathrm{R}$ radius of the cross-section

- $\rho_{s p}$ volumetric ratio of transverse reinforcement

- $s \quad$ spacing of the stirrups

- $v \quad$ axial load ratio

- $\omega$ mechanical ratio of longitudinal reinforcement

\section{APPENDIX A: DETAILED RESULTS}

Table 5: Coefficients of the polynomials: characteristics curvatures.

\begin{tabular}{|c|c|c|c|c|c|c|c|}
\hline & & $\chi_{\mathbf{Y c}}$ & $\chi_{Y}$ & $\chi_{P}$ & $\chi_{\mathrm{N}}$ & $\chi \mathrm{SP}$ & $\chi_{\mathrm{U}}$ \\
\hline$a_{0}$ & 0.000141687 & 0.0070035 & 0.0014652 & 0.013347 & 0.009525018 & 0.014913 & 0.030808 \\
\hline$a_{1}$ & 0.001179796 & -0.025165 & 0.0041811 & -0.054825 & -0.016328061 & -0.046539 & -0.11685 \\
\hline$a_{2}$ & 9.51055E-05 & -0.011074 & 0.00051892 & -0.030016 & -0.003856943 & -0.020517 & -0.073578 \\
\hline$a_{3}$ & 0 & 0 & 0 & 1.220752 & 0 & 0.010199 & 5.6901 \\
\hline $\mathrm{a}_{4}$ & 0.000641769 & 0.035666 & -0.0133308 & 0.083624 & 0.008869441 & 0.061621 & 0.15133 \\
\hline$a_{5}$ & -0.000996454 & 0.033249 & 0 & 0.085899 & 0.007162256 & 0.058635 & 0.19562 \\
\hline$a_{6}$ & 0 & 0.0072763 & -0.00027668 & 0.019272 & 0 & 0.012705 & 0.051627 \\
\hline$a_{7}$ & 0 & 0 & 0 & -2.225166 & 0 & 0 & -6.0449 \\
\hline$a_{8}$ & 0 & 0 & 0 & 0 & 0 & 0 & -5.1263 \\
\hline $\mathrm{a}_{9}$ & 0 & -0.017657 & 0.0087833 & -0.0442 & 0 & -0.028807 & -0.062491 \\
\hline$a_{10}$ & 0 & -0.020321 & 0.00045295 & -0.051413 & 0 & -0.034787 & -0.11249 \\
\hline$a_{11}$ & 0 & -0.013063 & 0 & -0.033684 & 0 & -0.022416 & -0.08808 \\
\hline a12 & 0 & 0 & 0 & 1.5519 & 0 & 0 & 1.7707 \\
\hline a13 & 0 & 0 & 0 & 0.95216 & 0 & 0 & 4.2011 \\
\hline a14 & 0 & 0 & 0 & -0.68209 & 0 & 0 & 1.3887 \\
\hline
\end{tabular}


Table 6: Coefficients of the polynomials: characteristics moments.

\begin{tabular}{|c|c|c|c|c|c|c|c|}
\hline & mCR & myc & my & $\mathbf{m P}$ & $\mathbf{m}_{\mathbf{N}}$ & mSP & $\mathbf{m u}_{\mathbf{U}}$ \\
\hline$a_{0}$ & 0.039104 & 0.030715 & 0.010733 & 0.054625 & 0.033077 & 0.05462 & 0.008101 \\
\hline$a_{1}$ & 0.24991 & 0.76049 & 0.90246 & 0.52452 & 0.62906 & 0.52452 & 0.691763 \\
\hline$a_{2}$ & 0.019069 & 0.56557 & 0.46595 & 0.59541 & 0.66 & 0.59541 & 0.79591 \\
\hline$a_{3}$ & 0 & 0.69419 & 0.25179 & -3.2 & -0.02506 & -3.19999 & 2.8189 \\
\hline$a_{4}$ & -0.1041 & -1.1359 & -1.4939 & -0.55922 & -0.60654 & -0.55922 & -0.77233 \\
\hline$a_{5}$ & 0.13464 & -0.91382 & -0.49555 & -0.17954 & -0.20421 & -0.17953 & -0.50387 \\
\hline$a_{6}$ & 0 & 0 & 0 & -0.02893 & -0.034895 & -0.02893 & -0.18153 \\
\hline$a_{7}$ & 0 & -2.8708 & 0 & 18.285 & 6.0638 & 18.2849 & 0 \\
\hline$a_{8}$ & 0 & -2.3298 & 0 & -1.68543 & -1.3176 & 8.39364 & 0 \\
\hline$a_{9}$ & 0 & 0.31306 & 0.58997 & 0 & 0 & 0 & -0.047563 \\
\hline$a_{10}$ & 0 & 0.80451 & 0.42036 & 0 & 0 & 0 & 0.50502 \\
\hline$a_{11}$ & 0 & 0 & 0 & 0 & 0 & 0 & 0.1109 \\
\hline$a_{12}$ & 0 & 3.3991 & 0 & 0 & 0 & 0 & 21.238 \\
\hline$a_{13}$ & 0 & 1.3589 & 0 & 0 & 0 & 0 & -11.155 \\
\hline$a_{14}$ & 0 & 0 & 0 & 0 & 0 & 0 & 6.6317 \\
\hline$a_{15}$ & 0 & 0 & 0 & 0 & 0 & 0 & -40.959 \\
\hline
\end{tabular}

Table 7: Test series RC sections, geometric and mechanical properties.

$\begin{array}{llllllllllll}\mathbf{D} & \mathbf{c} & \mathbf{n}_{\mathrm{l}} & \mathbf{d}_{\mathrm{l}} & \mathbf{d}_{\mathrm{h}} & \mathbf{s} & \mathbf{f}_{\mathrm{c}} & \mathbf{f}_{\mathrm{ys}} & \mathbf{N} & \boldsymbol{v} & \boldsymbol{\omega} & \rho_{s p}\end{array}$

$\begin{array}{llllllllllll}(\mathbf{m}) & (\mathbf{m}) & (-) & (\mathbf{m m}) & (-) & (\mathbf{m m}) & (\mathbf{M P a}) & (\mathbf{M P a}) & (\mathbf{M N}) & (-) & (-) & (-)\end{array}$

\begin{tabular}{llllllllllll}
\hline 1.2 & 0.06 & 18 & 26 & 14 & 60 & 30 & 380 & 23 & 0.678 & 0.107 & 0.010 \\
1.4 & 0.06 & 17 & 26 & 12 & 70 & 45 & 350 & 31 & 0.448 & 0.046 & 0.005 \\
1.5 & 0.06 & 15 & 32 & 14 & 70 & 26 & 380 & 12 & 0.261 & 0.100 & 0.006 \\
2.1 & 0.04 & 20 & 32 & 16 & 40 & 33 & 390 & 18 & 0.158 & 0.055 & 0.010 \\
2.5 & 0.04 & 23 & 20 & 16 & 50 & 42 & 500 & 75 & 0.364 & 0.018 & 0.007 \\
1.7 & 0.04 & 25 & 20 & 12 & 50 & 37 & 400 & 53 & 0.631 & 0.037 & 0.006 \\
1.6 & 0.07 & 19 & 26 & 14 & 50 & 48 & 360 & 70 & 0.726 & 0.038 & 0.008 \\
2.0 & 0.07 & 19 & 20 & 12 & 45 & 24 & 300 & 36 & 0.478 & 0.024 & 0.005 \\
2.3 & 0.07 & 25 & 18 & 16 & 40 & 29 & 350 & 66 & 0.548 & 0.018 & 0.009 \\
1.9 & 0.05 & 23 & 26 & 14 & 50 & 32 & 440 & 40 & 0.441 & 0.059 & 0.007 \\
\hline
\end{tabular}



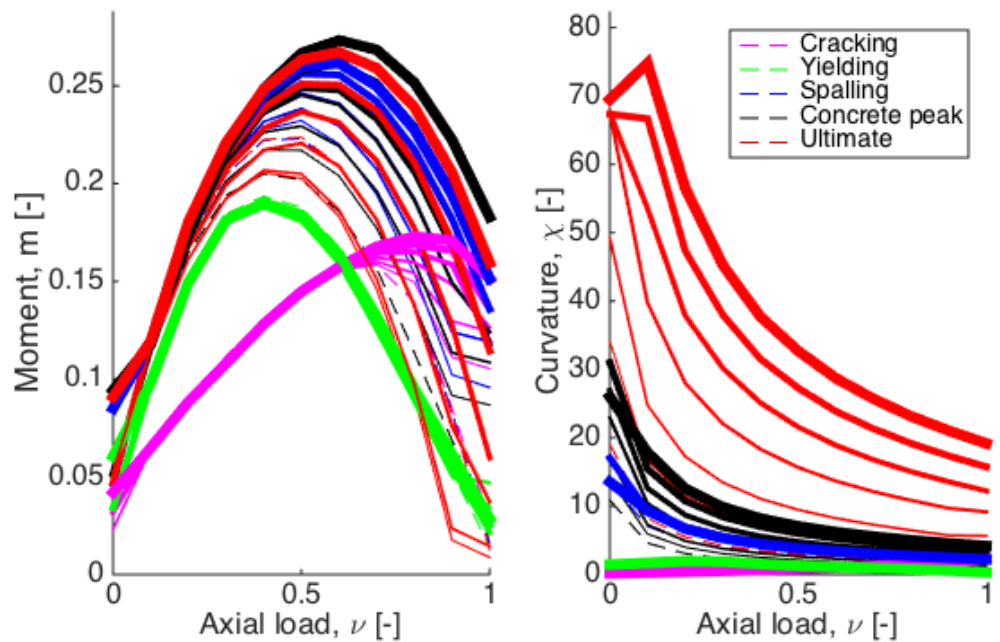

Figure 13: Trend of characteristic moments and curvatures for $\omega=0.05$ and the full range of $\rho_{\text {sp }}$.
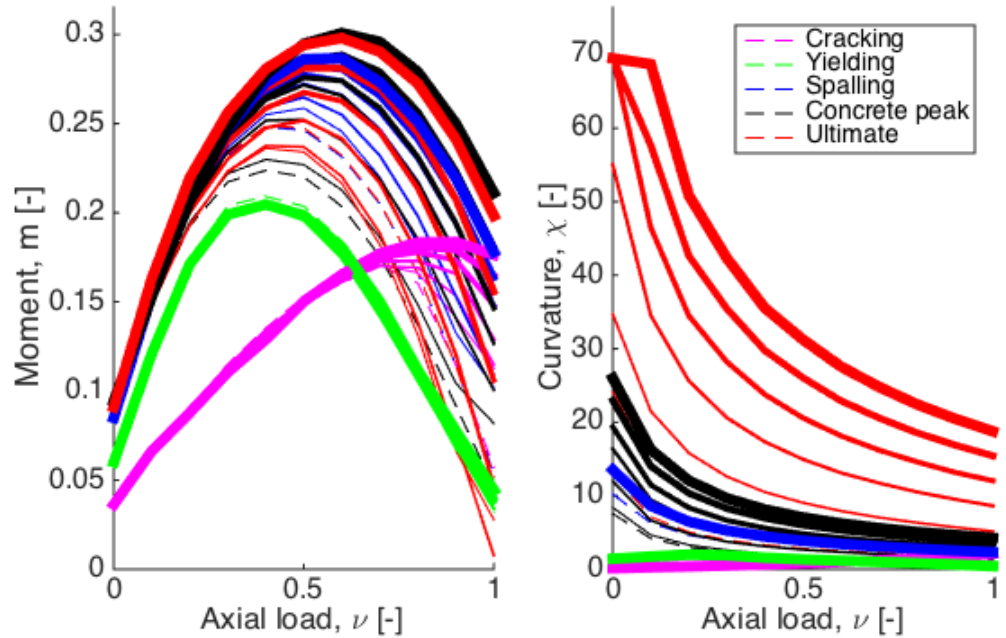

Figure 14: Trend of characteristic moments and curvatures for $\omega=0.1$ and the full range of $\rho_{s p}$.
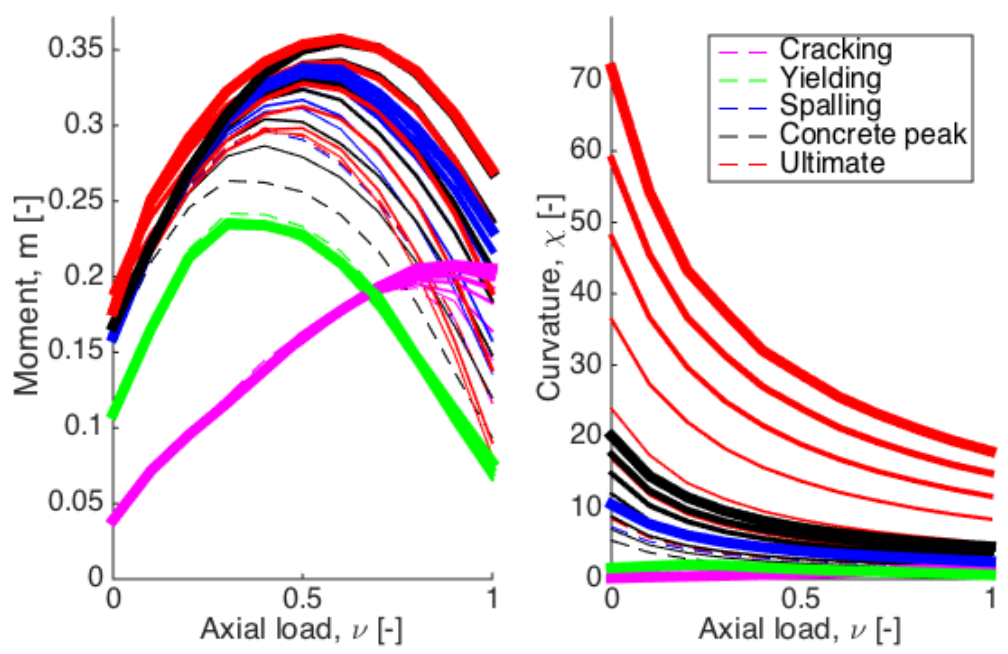

Figure 15: Trend of characteristic moments and curvatures for $\omega=0.2$ and the full range of $\rho_{s p}$. 

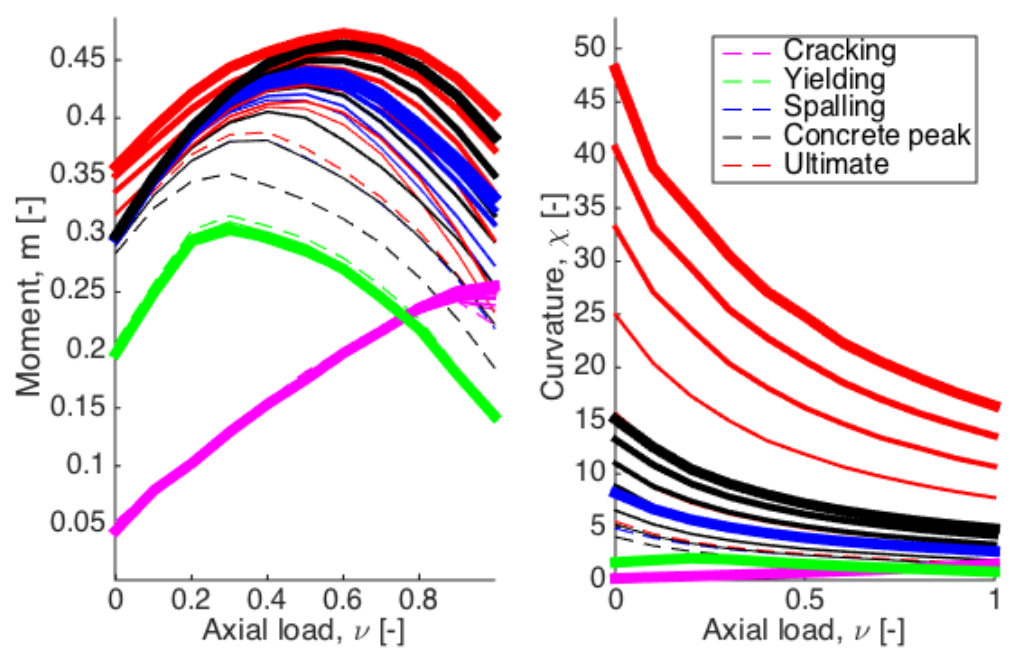

Figure 16: Trend of characteristic moments and curvatures for $\omega=0.4$ and the full range of $\rho_{s p}$.
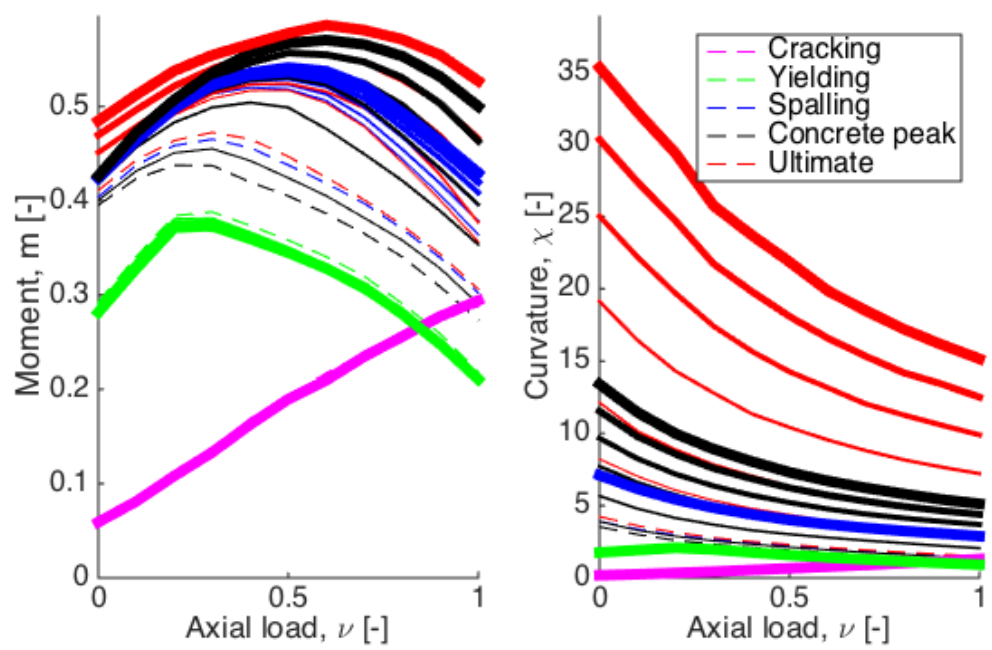

Figure 17: Trend of characteristic moments and curvatures for $\omega=0.6$ and the full range of $\rho_{s p}$.
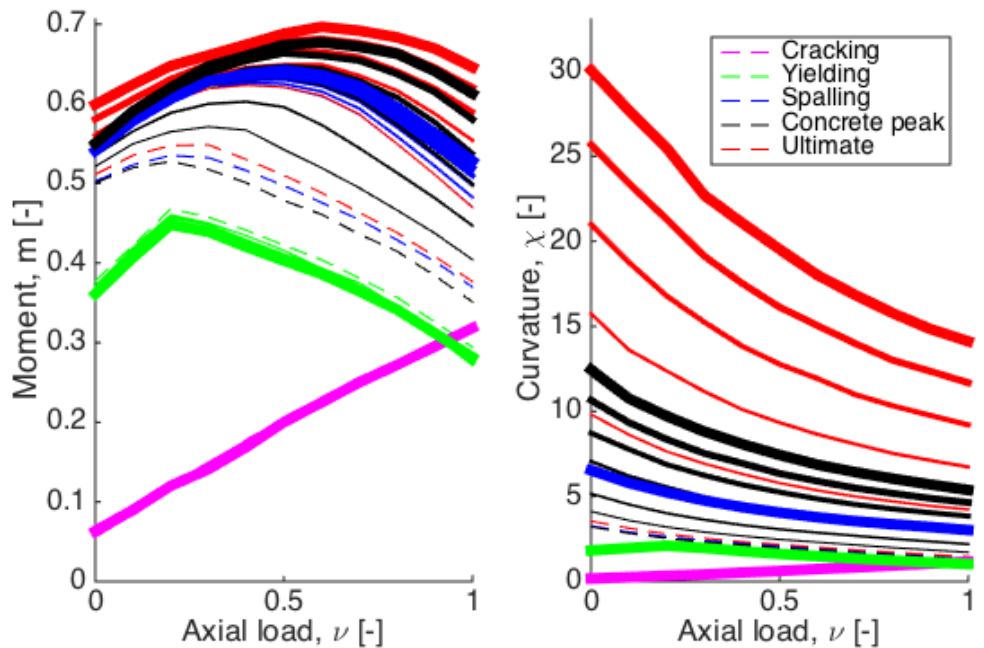

Figure 18: Trend of characteristic moments and curvatures for $\omega=0.8$ and the full range of $\rho_{s p}$. 